\section{The cycloheximide-induced amnesia gradient of a passive avoidance task*}

\author{
ELTON E. QUINTON† \\ University of Louisville, Louisville, Ky. 40208
}

Mice were injected with cycloheximide (cyc) or saline $45 \mathrm{~min}$ before passive avoidance training. They were tested $1,1.5,3,5,7,24$, or $72 \mathrm{~h}$ after training. A significant drop in the performance of the cyc animals was observed between the 3- and 5-h test intervals, a result similar to that found in maze studies. However, contrary to the results of maze studies, amnesia was evident as early as $1.5 \mathrm{~h}$ after training. Several possible explanations for this early appearance of amnesia are discussed, and it is suggested that the retraining procedure used in maze studies may have masked the early stages of amnesia.

In a series of studies, Barondes and his coworkers have studied the effects of inhibiting cerebral protein synthesis on the memory of a maze task (see Barondes, 1970, for an excellent review of his work). They have generally found that when mice are injected with cycloheximide (cyc) or acetoxycycloheximide and then trained in a maze to a minimal criterion at a time when their cerebral protein synthesis is inhibited $90 \%$ or more, the animals show marked amnesia when retrained $6 \mathrm{~h}$ or more after initial training but no amnesia when retrained $3 \mathrm{~h}$ or less after initial training. These authors have interpreted these results as indicating that the establishment of long-term memory is dependent upon protein synthesis during or shortly after learning, whereas short-term memory ( $3 \mathrm{~h}$ or less after learning) is independent of protein synthesis.

The purpose of the present study was to attempt an in-principle replication of the above findings with a passive avoidance (PA) task in order to test the generality of the above hypothesis and to determine whether cyc produces a gradient of amnesia for PA learning (which has been the most popular task for the study of amnesic agents) similar to the gradient found after maze learning. This test of the generality of the effects of cyc on memory seems necessary, since some published reports on the effects of cyc on PA memory are somewhat conflicting (Quartermain \& McEwen, 1970; Squire, Geller, \& Jarvik, 1971; Geller, Roubustelli, Barondes, Cohen, \& Jarvik, 1969).

$$
\text { METHOD }
$$

Male C57BL/6J mice, 22-26 g, were used in this study. They were housed six per cage, given food and water ad lib, and maintained on a 12 -h light

*This work was supported by NSF Departmental Grant GU 2628.

+Reprint requests should be sent to Elton E. Quinton. Laboratory of Psychobiology, Department of Psychology. University of Louisville. Louistille, Ky, 40208. 12 /group. injected with $.4 \mathrm{ml}$ of $0.15 \mathrm{M}$ saline or $.4 \mathrm{ml}$ of a cycloheximide (actidione, $\mathrm{NBC}$ ) solution (10 $\mathrm{mg} \mathrm{cyc} / \mathrm{ml}$ in $0.15 \mathrm{M}$ saline). The degree of inhibition of protein synthesis was determined by the method described by Barondes \& Cohen (1967) and was found to be $93 \%-95 \% 45 \mathrm{~min}$ after the injection of cyc.

The mice were given one training trial, then placed in a holding cage until all the animals of that group had been run, and then returned to their home cages. They were given a test trial $1,1.5,3,5,7,24$, or $72 \mathrm{~h}$ after training. During training, the step-through latency (STL) was measured as the time it took for the mouse to make contact with the metal floor after being placed on the platform. During testing, the STL was measured as the time it took the animal to enter into the chamber with all four feet after being placed on the platform (no shock on the test trials). If on the test trial an animal did not step into the chamber within $30 \mathrm{sec}$, the trial was terminated and the animal was assigned a step-through latency of 30 sec.

\section{RESULTS}

The median STLs on the training and test trials for all groups are presented in Fig. 1. An analysis of variance (Kruskal-Wallis) performed on the test-trial STLs of the cycloheximide groups over training-test intervals was significant

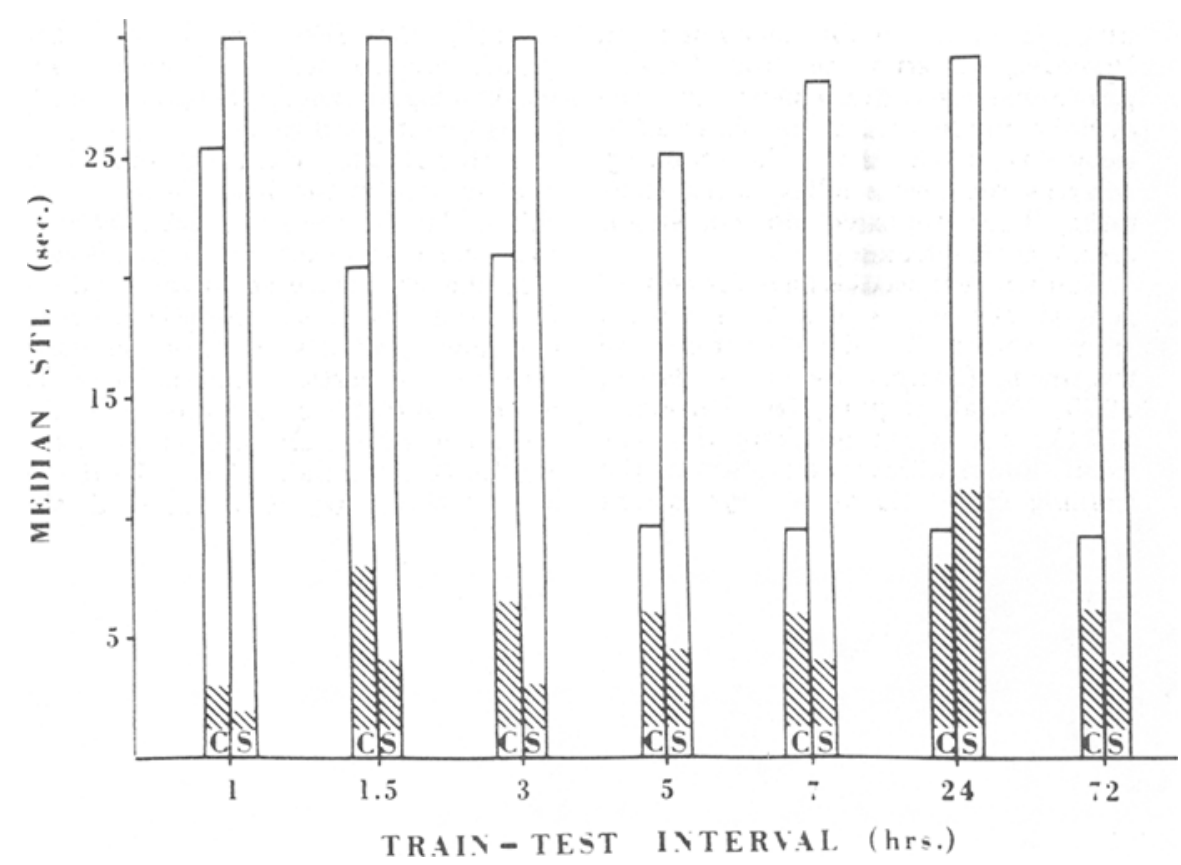

Fig. 1. Median test trial step-through latencies (STLs) at the various training-test intervals. The shaded part of the bar graphs represents the STLs on the training trial. $c=$ cycloheximide-injected mice; $s=$ saline-injected mice; $N=$ 
( $p<.01$ ), but a comparable analysis of the saline groups was not $(p>.1)$. The largest change in performance of the cycloheximide groups occurred between the 3- and 5-h groups (Mann-Whitney U, p <.05). This is similar to the results of Barondes and Cohen (1968), who found that the maximum change in performance occurred between the groups tested at 3 and $6 \mathrm{~h}$ after training.

However, in previous studies that utilized maze escape training (Barondes \& Cohen, 1968), no difference was found between the cycloheximide and saline groups when tested at $3 \mathrm{~h}$ after training, whereas in the present study, a significant difference (Mann-Whitney $U, p<.05$ ) was found between the groups tested at 1.5 or $3 \mathrm{~h}$ after training, as well as the longer test intervals $(p<.01)$ for the 5-, 7-, 24-, and 72-h intervals). It was also found that the mean training trial STL for the pooled cycloheximide groups was significantly greater than the pooled saline groups (two-tailed $t$, $\mathrm{p}<.05$ ).

\section{DISCUSSION}

The results of this study indicate that the temporal gradient of amnesia following cycloheximide treatment and PA training is somewhat similar to the gradient following escape training (Barondes \& Cohen, 1968), insofar as there is a marked decrease in "memory" between 3 and $5 \mathrm{~h}$ (or 6) after training. This suggests that this part of the cycloheximide-induced amnesia syndrome is not task specific but is a general phenomenon. However, this study also found that a performance decrement in the cycloheximide Ss can be observed as early as $1.5 \mathrm{~h}$ after PA training, whereas previous studies, using maze tasks, have reported no decrement until $6 \mathrm{~h}$ after training.

Some recent studies have found that general activity is less than normal from about 1 to $3 \mathrm{~h}$ after cyc treatment (Squire, Geller, \& Jarvik, 1970; Segal, Squire, \& Barondes, 1971 ), and it seems likely that the small, but significant, elevation of the training trial STL of the cyc groups reflects this decreased activity. It seemed possible, therefore, that the early appearance of a performance decrement at $1.5 \mathrm{~h}$ may have also been due to some secondary effect of the drug on PA performance (such as disorientation, hypersensitivity to light, etc.) rather than to amnesia.

Therefore, a control study was run to determine if the impaired test trial performance of the cyc-treated mice could have been caused by some secondary, nonamnesic, effect of the drug. Four groups of mice ( $N=12$ /group) were given PA training ard then injected with $4 \mathrm{mg}$ of cyc or saline on the following day. One cyc and one saline group were given the test trial 2.25 or $5.75 \mathrm{~h}$ after the injections, corresponding to the train-test intervals of 1.5 and $5 \mathrm{~h}$ in the original experiment. All four groups had median STLs of $30 \mathrm{sec}$ on the test trial. Therefore, it seems very unlikely that the impaired test trial performance observed in the original study could have been due to some secondary, nonamnesic, effect of cyc on PA performance.

It is possible that the drug may have impaired the learning ability of the mice so that their early poor performance reflected inferior conditioning rather than memory impairment. However, the absence of a significant difference between the groups tested at $1 \mathrm{~h}$ tend to argue against this, although it is possible that had the criterion test latency been longer (i.e., less chance of a "ceiling effect"), the difference between the groups tested at $1 \mathrm{~h}$ might have reached significance. This possibility is being investigated further.

Perhaps the most parsimonious explanation for the difference between this study and previous maze studies in the time of appearance of amnesia is that the PA task used in this study is more sensitive to the amnesic effect of cyc and provides a more sensitive measure of partial amnesia than do maze tasks. It is possible that the retraining procedure used in the maze studies (see Barondes, 1970; Barondes et al, 1968) may have masked the appearance of the early stages of amnesia. The animals may have been experiencing partial amnesia $3 \mathrm{~h}$ after training, but they relearned the task to criterion so easily that the effects of the partial amnesia were quickly overcome and not reflected in the "savings score" which Barondes and others have used to measure amnesia.

In support of this suggestion, it has been found in this laboratory that mice preinjected with cyc and trained to a criterion of three out of four (or five out of six) conditioned avoidance responses in a jump-up box (a task which they learn very easily) do not differ from saline-injected mice when they are retrained to the same criterion and their savings scores are compared but do differ significantly when only the performance on the first retraining trial is compared.

$$
\text { REFERENCES }
$$

BARONDES, S. H. Cerebral protein synthesis inhibitors block long-term memory. International Review of Neurobiology, 1970,12, 177-205.

BARONDES, S. H., \& COHEN, H. D. Delayed and sustained effect of acetoxycycloheximide on memory in mice. Proceedings of the National Academy of Sciences, 1967.58, 157-169.

BARONDES, S. H., \& COHEN, H. D. Arousal and the conversion of "short-term" memory. Proceedings of the National Academy of Science, 1968.61. 923-929.

ESSMAN, W. B., \& ALPERN, H, P. Single trial conditioning: Methodology and results with mice. Psychological Report. $1964,14,731-740$.

GELLER, A.. ROBUSTELLI, F. BARONDES, $S$. H., COHEN, H. D., \& JAR VIK, M. E. Impaired performance by post-trial injections of cycloheximide in a pasive avoidance task. Psychopharmacologia. 1969, 14, 371-376.

HERZ, M., PEEKE, V. S., \& WYERS, J. Amnesic effects of ether and electroconvulsive shock in mice. Psychonomic Science, 1966, 4, 375-376. QUARTERMAIN, D., \& McEWEN, B. Temporal characteristics of amnesia induced by protein synthesis inhibitor: Determination by shock level. Nature, $1970,228,677-678$.

SEGAL, D. S., SQUIRE, L., \& BARONDES, $S$. Cycloheximide: Its effects on activity are dissociable from its effects on memory. Science, 1971, 172, 82-84.

SQUIRE, L.. GELLER, A., \& JARVIK, M. Habituation and activity as affected by cycloheximide. Communications in Behavioral Biology, 1971, 5, 249-254. 